\title{
TAPICES DONADOS POR LOS REYES CATÓLICOS A LA CAPILLA REAL DE GRANADA*
}

\author{
Miguel Ángel Zalama \\ Universidad de Valladolid
}

Entre las principales piezas que los Reyes Católicos enviaron a la Capilla Real de Granada se cuentan varios tapices. Isabel de Castilla y Fernando de Aragón habían adquirido muchos ejemplares a lo largo de los años, de manera que cuando la reina murió, tenía más de trescientos paños. Su marido quiso enviar veintidós a la capilla funeraria que habían fundado. Cuando el rey estaba próximo a morir, quiso aumentar el número de tapices incorporando otros cuatro de su tesoro. Sin embargo, hubo cambios y al final solo veinticinco piezas ingresaron en la Capilla Real, en parte diferentes a la primitiva idea. Ahora, a partir de documentos inéditos conservados en el Archivo General de Simancas, por primera vez podemos demostrar cuántos y cuáles fueron los tapices que se enviaron, lo que permite acercarse al verdadero valor de los tapices en los tesoros en los siglos XV y XVI.

Palabras clave: Capilla Real; Granada; Reyes Católicos; Tapices.

\section{TAPESTRIES DONATED BY FERDINAND AND ISABELLA TO THE ROYAL CHAPEL IN GRANADA}

Among the principal items sent by Ferdinand and Isabella to the Royal Chapel in Granada were several Flemish tapestries. Isabella of Castile and Ferdinand of Aragon acquired many pieces over the years, so that when the Queen died, she owned more than three hundred wall-hangings. Her husband decided to send twenty-two of them to the funerary chapel they had founded, and when he was close to death, he ordered four more to be sent from his own treasure. Nevertheless, changes occurred, and finally twenty-five pieces arrived at the Royal Chapel, but they were not all the same as those originally selected. Now, based on unpublished documents preserved in the Simancas Archive (Valladolid), it is possible to demonstrate for the first time exactly which and how many tapestries were actually sent, further revealing their true value in the treasures of the $15^{\text {th }}$ and $16^{\text {th }}$ centuries.

Key words: Royal Chapel; Granada; Ferdinand; Isabella; Tapestries.

Cuando la enfermedad que padecía Isabel la Católica indicaba un trágico y pronto final, los monarcas decidieron erigir una capilla, donde "serán nuestros cuerpos sepultados", anexa a la

* Este trabajo se ha realizado en el marco del Proyecto de Investigación del Ministerio de Economía y Competitividad de España HAR2010-16474/ARTE Los tapices de los Reyes Católicos y Juana I. Las colecciones y su dispersión. 
catedral de Granada, en la ciudad que se había convertido en el símbolo de su reinado ${ }^{1}$. La orden es del 13 de septiembre de 1504, ratificada el último día de ese mismo mes ${ }^{2}$, por lo que cuando doña Isabel hizo testamento el 12 de octubre no había dado tiempo ni a proyectar el edificio. De hecho, no se podía haber iniciado porque en la orden de los monarcas se especificaba que la dotación de la capilla -373.000 maravedís anuales, de los cuales 100.000 se destinaban "para la fábrica de la dicha capilla e para los hornamentos e para la çera e azeyte e gastos de la sacristía e para todas las cosas que generalmente fueren necesarias..."-, saldrían de las rentas de la corona en Granada y su arzobispado, y empezarían a devengarse "desde primo día del mes de henero del año que vyene de mill e quinientos e çinco años en adelante en cada vn año"3.

Urgía, pues, fijar un lugar donde provisionalmente depositar el cuerpo de la reina, fallecida el 26 de noviembre de 1504, hasta que la capilla que había fundado estuviese concluida. Isabel la Católica fue consciente de ello y en su ultima voluntad dispuso que se le enterrara en el monasterio de San Francisco de La Alhambra, si bien dejaba abierta la posibilidad de un cambio "si el rey mi señor eligiere sepultura en otra qualquier iglesia o monasterio de qualquier otra parte o lugar destos mis reynos, que mi cuerpo sea allí trasladado e sepultado junto con el cuerpo de su señoría...”. En esta cláusula de su testamento no se hace referencia a la Capilla Real, sin duda por no existir ésta nada más que sobre el papel, pero la soberana no se olvidó de su fundación y ordenó "que si la capilla real que yo he mandado hacer en la iglesia cathedral de San María de la $\mathrm{O}$ de la çibdad de Granada no estouiere fecha al tiempo de mi fallesçimiento, mando que se haga de mis bienes o lo que della estouiere por acabar, segund yo lo tengo ordenado e mandado"4.

Fernando el Católico, en tanto que testamentario de su esposa y cofundador de la capilla, quiso llevar adelante el proceso constructivo, de manera que el 14 de marzo de 1505 ordenó que se comenzasen los trabajos 5 . Puso al frente de la fundación al limosnero Pedro García de Atienza y como mayordomo de la construcción a Fernando Arias de Rivadeneira, a quien se obligaba a "residir en las obras porque aya buena diligencia en ellas". El rey de Aragón quería que el edificio se erigiese con rapidez, y en la década que aún viviría en diferentes ocasiones mostró su preocupación por la capilla que a la postre también iba a ser su última morada ${ }^{6}$. No obstante, la escasa dotación para la fábrica -100.000 maravedís anuales de los que había que descontar el gasto en ornamentos, cera, aceite..., e incluso separar 14.080 para los canónigos que asistieran en los dos principales aniversarios ${ }^{7}$ y los acontecimientos que siguieron a la muerte de la soberana, propiciados por la incapacidad de su heredera, Juana I, que supusieron la pugna entre Fernando el Católico, dispuesto a retener el gobierno de Castilla, y el esposo de la nueva reina, Felipe el Hermoso, que se saldó con el triunfo de éste y la marcha del rey de Aragón ${ }^{8}$, paralizaron el proyecto.

Castilla quedaba en manos de Felipe I y no parece que entre sus principales intereses estuviera la construcción de la capilla fundada por sus suegros. Sin embargo, un suceso inesperado

\footnotetext{
${ }^{1}$ Archivo General de Simancas (AGS), Patronato Real (PR), leg. 25, doc. 42: “mandamos que en la yglesia catedral de Nuestra Señora Santa María de la O de la çibdad de Granada se faga vna honrada capilla a la mano derecha de la capilla mayor de la dicha yglesia en la qual serán, quando la voluntad de nuestro Señor fuere, nuestros cuerpos sepultados, la qual dicha capilla se a de llamar de los Reyes e ser a la vocaçión de san Juan bautista e san Juan evangelista...".

2 Gallego y Burín, 1931: 19.

3 AGS, PR, leg. 25, doc. 42 .

${ }^{4}$ AGS, PR, leg. 30, doc. 2.

5 AGS, PR, leg. 25, doc. 43 .

${ }^{6}$ Gallego y Burín, 1931: 22. Rosenthal, 1973-1974: 13-36. Alonso Ruiz, 2006: 341-343. Alonso Ruiz, 2007 : 131-140.

7 AGS, PR, leg. 25, doc. 42. El capellán mayor tenía una asignación de 50.000 maravedís anuales, lo que da una idea clara de la pobre asignación para la fábrica.

8 Zalama, 2010:185-201.
} 


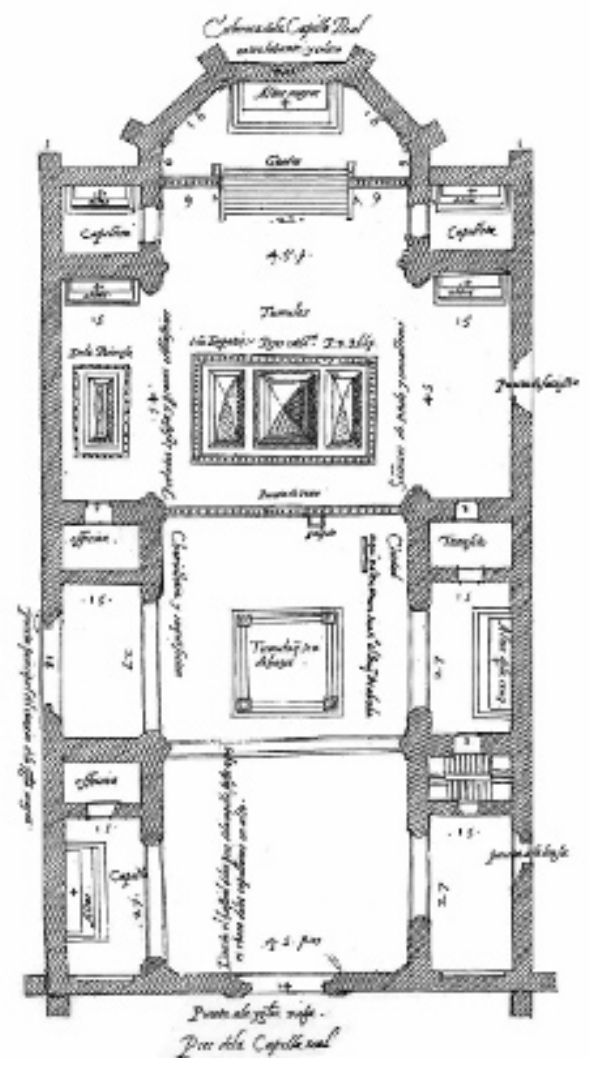

Fig. 1. Capilla Real de Granada (planta), 1574. AGS, Patronato Eclesiástico, leg.150-52. (Publicado por Redondo Cantera: 2006, 417).

hizo que incluso en ausencia del rey Fernando, que se había trasladado a Italia, se diese la orden de comenzar los trabajos. Felipe el Hermoso falleció inopinadamente el 25 de septiembre de 1506 en Burgos, y en su testamento, que había redactado poco antes de abandonar los Países Bajos, mandaba que si moría en España se le llevase a enterrar a "Grenade avec le feue royne d'Espagne ma belle mère" 9 . Esta disposición, cuyo cumplimiento se convirtió en obsesión para Juana I, llevó a que el arzobispo de Toledo, Cisneros, a la postre gobernador de Castilla ante la inacción de la reina y la ausencia de su padre, tomara junto a los demás testamentarios de Isabel la Católica la decisión de comenzar inmediatamente la fábrica, por lo que solo cinco días después de fallecer Felipe I se concertó con Enrique Egas la erección de la Capilla Real ${ }^{10}$.

La construcción al final fue más lenta de lo que se había previsto ${ }^{11}$, pero aun sin haberse concluido, Fernando el Católico, que en 1514 contrató los sepulcros con el italiano Domenico Fancelli, quiso que se enviaran ornamentos, platería litúrgica, reliquias y obras de arte del tesoro de su esposa, además de lo que él mismo donó. Entre esos objetos destacan los tapices, tenidos por verdaderas joyas por sus poseedores y que eran apreciados en cantidades mucho más elevadas que las pinturas ${ }^{12}$. Hasta donde sabemos, ninguno de los paños que los Reyes Católicos donaron a su capilla ha llegado a nuestros días ${ }^{13}$, aunque ahora sí tenemos memoria cierta de cuántos y cuáles fueron.

\section{Tapices de Isabel la Católica enviados a la Capilla Real}

En su testamento la reina Católica no especificó cuáles de sus bienes debían ir a la Capilla Real. Que no se hubiese comenzado a edificar debió ser razón suficiente para que doña Isabel declarase como receptora de "los ornamentos de mi capilla" a "la iglesia de la çibdad de Granada".

\footnotetext{
9 Zalama, 2010: 208.

10 AzCÁRATe, 1982: 104-114.

${ }_{11}$ Aunque hay importantes aportaciones recientes, en esencia el proceso constructivo está en GómEZ-MoRENO, 1925: 245-288, y GALLEGO Y BURíN, 1931.

12 Zalama, 2008: 43-64.

13 En estudios recientes sobre los tapices que pertenecieron a la reina Católica -Herrero Carretero, 2004; DeLmarCel, 2005- no se encuentra ningún tapiz de los conservados que pueda identificarse con los que se enviaron a la Capilla Real. Lo mismo puede decirse de los que formaban parte del tesoro del rey Fernando. ZALAma y PASCUAL MoLINA, 2012.
}

Arch. esp. arte, LXXXVII, 345, ENERO-MARZO 2014, 1-14

ISSN: 0004-0428, eISSN: 1988-8511, doi: 10.3989/aearte.2014.01 
Indicación demasiado vaga que se precisa en la manda que continúa: "suplico al rey mi señor se quiera seruir de todas las dichas joyas e cosas o de las que a su señoría más agradaren..."14. Fernando el Católico no dudó en hacerse con los objetos que mejor le parecieron, pero también tomó a su cargo dotar la Capilla Real, a la que destinó algunos tapices de considerable valor.

La primera nómina que registra el envío de paños a la Capilla Real data del 14 de marzo de 1505, el mismo día en que se ordenó iniciar el edificio ${ }^{15}$. Los testamentarios de Isabel la Católica entregaron a Pedro García de Atienza, limosnero de la reina, un considerable número de piezas, que pertenecían al tesoro de doña Isabel y estaban a cargo del camarero Sancho de Paredes. Entre ellas se contaban once tapices, ocho de los cuales se habían comprado a Matis de Guirla, a quien en diferentes registros se le denomina "mercader flamenco", a principios de 1504, pues pasaron a manos del camarero el 15 de enero de ese año ${ }^{16}$. Eran de pequeño tamaño, entre dos y tres metros de anchura - de 2,5 a 3,5 varas, aunque a veces se da la superficie del paño en anas ${ }^{17}$, , salvo uno que superaría los cinco metros. Realizados en seda y lana y guarnecidos, menos el octavo que mostraba a Santa Bárbara los demás se referían a la vida de Cristo. Como es habitual en los tapices realizados a finales del siglo XV contenían varias escenas, si bien cada paño se identifica por una historia principal: Crucifixión, Ecce Homo, Prendimiento, Cristo y la samaritana, Pilatos se lava las manos, el Lavatorio y la Huida a Egipto. Atendiendo a la temática y a que en los tres primeros se describe una orla similar, definida por "vnas viñetas verdes", quizá formasen una serie, si bien presentaban diferencias de tamaño y sobre todo de calidad, pues se tasaron en cantidades dispares, desde los 450 maravedís el ana del paño de la Huida a Egipto, a los 1.000 maravedís en que se apreciaron el Prendimiento o el Lavatorio. En total superarían los cien mil maravedís, pues aunque del primero no se especifica el precio en que se adquirió, los otros siete sumaron más de 94.000 maravedís. Es decir, una media de unos 13.500 maravedís cada paño, lo que los convierte en piezas importantes si bien menos que otros tapices en los que se incluían hilos de oro y que podían multiplicar esa cantidad varias veces.

Tres días después de que estos ocho tapices se entregaran a Sancho de Paredes, el camarero recibió otros tres, "en la villa de Medina del Campo a diez y ocho de enero de quinientos e quatro año" "18. El primero de los tapices tenía el Nacimiento de Cristo como escena principal y se decía que era pequeño, aunque alcanzaba diecisiete anas, por cada una de la cuales se pagaron 850 maravedís. El segundo, también catalogado como pequeño, pues solo tenía doce anas, representaba el Apocalipsis, y se especifica que se compró a Alonso de la Torre por 620 maravedís el ana. El último de este lote, de 35 anas, contenía varias historias -Salutación, Circuncisión...- y también se adquirió de Alonso de la Torre a un precio similar, 650 maravedís el ana ${ }^{19}$. Los tres sumaban 48.140 maravedís, de los que más de la mitad correspondían al último, el de mayor tamaño, pero no alcanzaban la calidad de algunos de los anteriores a juzgar por las cantidades pagadas. Aunque se omite el nombre del mercader en el primer paño, es más que probable que

${ }^{4}$ AGS, PR, leg. 30, doc. 2.

15 AGS, Contaduría Mayor de Cuentas (CMC), 1. Época, leg. 186, s/f. Existen copias, con importantes variantes, en el leg. 189 s/f y, especialmente, en el leg. 959, s/f. Los asientos contenidos en el primer legajo los publicó Sánchez Cantón, 1950: 118-121, incompletos y sin mencionar que se enviaron a la Capilla Mayor de Granada, pues no se precisa cuál fue su destino en el documento, lo que sí se expresa de manera explícita en el legajo 189 s/f, e incluso de forma más completa en el leg. 959. Véase Apéndice documental.

$16 \mathrm{AGS}, \mathrm{CMC}, 1 .^{\mathrm{a}}$ Época, leg. 186, s/f. "el qual reçebistes en la villa de Medina del Campo a quinze días del mes de enero de mill e quinientos e quatro años". SÁNCHEZ CANTÓN, 1950: 119-120, omite esta fecha de entrega al camarero Sancho de Paredes, que se repite en todos los tapices, y equivocadamente considera que los paños llegaron a su poder tres años antes, el 7 de enero de 1501.

17 Una vara, $835,9 \mathrm{~mm}$, equivale a 1,2 anas.

18 Véase Apéndice documental.

19 AGS, CMC, 1. . Época, leg. 959, s/f.

Arch. esp. arte, LXXXVII, 345, ENERO-MARZO 2014, 1-14 ISSN: 0004-0428, eISSN: 1988-8511, doi: 10.3989/aearte.2014.01 
fuese el mismo del que se adquirieron los otros dos, pues se entregaron a la vez al camarero Paredes.

Estos once tapices fueron enviados a la Capilla Real en marzo de 1505, a los que se sumaron otros tantos cuatro meses después. Por nómina del rey de Aragón de 22 de julio de 1505 firmada en Segovia, se entregaron al capellán real Martín Velázquez once paños "para los llevar a la dicha Capilla Real de Granada" ${ }^{20}$. Los tapices formaban parte del tesoro de Isabel la Católica custodiado en el alcázar de Segovia y se anotaron como: "Vn paño en que están los santos de España e Nuestra Señora en medio con el Niño en los braços, de mucha seda syn oro, son de largo diez varas largas e de cayda çinco varas largas". "Otro paño del desposorio de Nuestra Señora que tiene vn pabón a vn cabo haziendo la rueda, tiene oro e mucha seda, tyene de largo diez varas e terçia e de cayda çinco varas e quarta". "Otro paño de la transfiguraçión de Nuestro Señor en que está Dios Padre al cabo de la mano derecha del paño, ay en él dos rótulos baxos e tyene mucha seda, tiene de largo diez varas e quarta e de cayda çinco varas e media, no tiene oro, está sin guarnisçión". "Otro paño de la ystoria de la rayz de Jesé en que está Nuestra Señora con vna bestidura azul con el Niño en los braços e otras muchas figuras, y tiene mucha seda e tiene de largo onze varas y media e de cayda çinco varas". "Otro paño pequeño con vn Cruçifixo e Nuestra Señora e san Juan, tiene tres escudos de las armas de Castilla e León e Aragón, e tiene de largo tres varas y quarta e de cayda quatro varas y quarta e tiene mucha seda". "Otro paño de la muger acusada en adulterio de muchas figuras con vnos letreros por la parte de abaxo de mucha seda, tiene de largo treze varas escasas e de cayda çinco escasas, tiene entre cada letrero vn árbol de colores". "Otro paño pequeño de deboçión en que está la salutaçión de Nuestra Señora e el nasçimiento de Nuestro Señor, tiene de largo quatro varas e de cayda quatro varas e media". "Otro paño pequeño de lana y seda de la Quinta Angustia, tiene de largo tres varas y tres quartas e de caída quatro varas e media". "Otro paño pequeño de deboçión de seda y lana en que están tres cruçifixos, tyene de largo çinco varas e de cayda quatro varas e media". "Otro paño grande de lana y seda que es de los syete sacramentos y tiene por medio syete letreros de letras negras, tiene de largo diez e seys varas e tres quartas e de cayda çinco varas e tres quartas".

El inventario donde se incluyen estos diez paños, junto a otros muchos que estaban a cargo de Rodrigo de Tordesillas en el alcázar de Segovia, lo publicó por primera vez José Ferrandis, sin declarar que se enviaron a la Capilla Real ${ }^{21}$. Pocos años después Sánchez Cantón incluyó el inventario en su estudio sobre los tapices, pinturas y cuadros de la reina Isabel, con una nota al pie de página en la que se declaraba que se habían entregado a Martín Velázquez, capellán de los reyes en la Capilla Real, junto con otro paño del que solo decía que mostraba la Anunciación y Cristo en la cruz entre los ladrones ${ }^{22}$. Este último es el que se cita junto a los diez anteriores, en un documento hasta ahora inédito, como: "Otro paño grande de deboçión de lana y seda y oro que tyene en medio el cruçifixo con los ladrones y a la mano derecha la salutaçión de Nuestra Señora, tiene de largo quinze varas e de cayda quatro varas y media"23.

Se trataba de un magnífico conjunto de once tapices de diversos tamaños, algunos muy grandes como el que alcanzaba "de largo diez e seys varas e tres quartas" (14 metros). Manufacturados en lana y seda, estos paños a diferencia de los enviados en primer lugar carecen de tasación, si bien se encuentran inventariados junto a otros que se apreciaron en torno a 30.000 maravedís, como es el caso de uno de la historia de Hércules de cerca de 14 varas por 6 de caída, que se estimó en 30.400 maravedís ${ }^{24}$. Los de menor tamaño tendrían un precio inferior, si bien en cual-

${ }^{20}$ AGS, CMC, 1. Época, leg. 959, s/f. Con algunas variantes la documentación se repite en PR, leg. 30, doc. 6, fol. LX, pero aquí no se dice que se enviaron a la Capilla Real de Granada.

21 Ferrandis, 1943: 143-144. AGS, PR, leg. 30, doc. 6, fol. LIX.

22 SÁNCHEZ CANTÓN, 1950: 97, nota n. ${ }^{\circ} 57$.

23 AGS, CMC, 1. ${ }^{a}$ Época, leg. 959, s/f.

24 AGS, CMC, 1. . Época, leg. 959, s/f.

Arch. esp. arte, LXXXVII, 345, ENERO-MARZO 2014, 1-14

ISSN: 0004-0428, eISSN: 1988-8511, doi: 10.3989/aearte.2014.01 
quier caso se trataba de piezas muy costosas, lo que demuestra el interés de los monarcas (habría que precisar Fernando el Católico) en su fundación.

No hay duda del envío de estos segundos once tapices; la documentación es clara y hasta reiterativa al respecto: "Los quales dichos paños de suso contenidos se dieron e entregaron a Martín Velázquez capellán de sus altezas de la Capilla Real de la çibdad de Granada por nómina del rey nuestro señor e de los testamentarios de la Reyna nuestra señora que santa gloria aya, fecha en la çibdad de Segouia a veynte e dos días de jullio de mill e quinientos e çinco años, segund paresçe por el conosçimiento que dellos dio el dicho Martín Velázquez que está en las espaldas de la dicha nómina original, los quales se le entregaron para los llevar a la dicha Capilla Real de Granada" 25 .

En total fueron veintidós los tapices que procedentes del tesoro de Isabel la Católica se dispusieron para llevar a la Capilla Real de Granada, aunque uno parece que nunca llegó. De los once primeros se desconocía su destino mientras que de los últimos se entendió que formaban parte de un envío junto a otros ocho, de manera que supuestamente habían ingresado diecinueve paños. No fue así y en ello parece que Fernando el Católico tuvo mucho que ver.

\section{Participación de Fernando el Católico en el legado de tapices a la Capilla Real}

Sin la intervención del rey de Aragón quizá no hubiesen llegado los paños a la Capilla Real, pues Isabel la Católica no dejó una manda clara en su última voluntad y fue su esposo quien, de acuerdo con los demás testamentarios de la reina, dio la orden de realizar sendas entregas, en marzo y en julio de 1505. No hay duda de que la decisión de Fernando el Católico fue determinante, sin embargo parece que el número de paños iba a ser mayor y que en el último momento el rey decidió retirar nueve piezas que ingresaron en su tesoro: seis paños que formaban una serie relativa a la historia de Hércules y otros tres conocidos como de la historia del Peregrino.

Los seis de la historia de Hércules eran de mayor tamaño y se apreciaron en 400 maravedís cada ana, veinticinco más que los que componían la serie del Peregrino. Se trataba de "vn paño de la ystoria de Hércoles en que está Hércoles armado que ha herido con vna saeta a vn onvre medio onbre y medio cavallo [...] tyene de largo ocho varas y media e de cayda seys varas largas, que son por anas quinze anas de largo y de cayda syete anas y vna quarta, ay en todo el dicho paño çiento e diez anas e vna quarta, que montó a rasón de quatroçientos maravedís la ana, quarenta e quatro mill e çient maravedís. Otro paño de la dicha ystoria de Hércoles en que está Hércoles armado de vnas armas blancas con vn cuero de vn león y está el rey Caco [...] tyene de largo diez e syete anas e de cayda seyte anas e vna terçia, que ay en todo el dicho paño çiento e veynte e tres anas, a rasón de quatroçientos maravedís la ana montó quarenta e nueve mill e dozientos maravedís. Otro paño de la misma ystoria de Hércoles de quando entró en el ynfierno y sacó a Proserpina en que ay otras muchas figuras de mucha seda, tiene de largo quinze anas e tres quartas e de cayda syete anas e vna quarta que ay en todo el dicho paño çiento e diez e seys anas y dos quartas a rasón de quatroçientos maravedís la ana, montó quarenta e çinco mill e seysçientos maravedís. Otro paño de la dicha ystoria de Hércoles con vn puerco peleando [...] de largo quatorze anas e vna terçia e de cayda syete anas, que son todas noventa e vna anas e vna quarta, a rasón de quatroçientos maravedís la ana montó treynta e syete mill e tresçientos maravedís. Otro paño de la dicha ystoria de Hércoles en que está peleando Hércoles con vna bestia y vn toro y está ençima del del [sic] toro vnas letras que dizen Arquelaus [...] que ay en todo el dicho paño çiento e treynta e seys anas e vna quarta, a rasón de quatroçientos maravedís la ana montó LIIII U CCCC maravedís. Otro paño de la dicha ystoria de Hércoles en que están

${ }^{25}$ AGS, CMC, 1. a Época, leg. 959, s/f.

Arch. esp. arte, LXXXVII, 345, ENERO-MARZO 2014, 1-14 ISSN: 0004-0428, eISSN: 1988-8511, doi: 10.3989/aearte.2014.01 
tres leones que ha muerto y el nasçimiento de Hércoles [...] ay en todo el dicho paño setenta e seys anas e tres quartas a rasón de quatroçientos maravedís la ana, montó treynta mill e quatroçientos maravedís"26.

La serie de la historia del Peregrino sigue la obra del monje cisterciense francés Guillaume de Deguilleville, quien en 1331 escribió Le pélerinage de la vie humaine, libro de gran difusión que se tradujo a diversos idiomas -en español hay una versión de fray Vicente Maçuelo de mediados del siglo $\mathrm{XV}^{27}$ - y que fue tema frecuente en las tapicerías al finalizar la Edad Media. La serie que pertenecía a Isabel la Católica estaba compuesta por tres paños grandes, de cerca de 8 metros de anchura, que tenían mucha seda pero que alcanzaron una tasación de 375 maravedís por cada ana, algo inferior a la establecida por los de Hércules. Se inventariaron como "...vn paño de la ystoria del peregrino en que está el pelegrino del mundo metido en vna fuente e con otras muchas figuras de mucha seda, tiene de largo doze anas e de cayda seys anas que asy en todo el dicho paño setenta e dos anas, a razón de tresientos e setenta e çinco maravedís la ana, montó veynte e syete mill maravedís. Otro paño de la dicha ystoria del peregrino en que está el peregrino e tiene en medio vna muger con vnas letras ençima e dizen graçia dey e otras muchas figuras del mismo largo e cayda del susodicho, que ay en todo el dicho paño otras setenta e dos anas al dicho respecto de vn ducado cada ana montó otros veynte e syete mill maravedís. Otro paño de la dicha ystoria del peregrino en que está el peregrino bestido con vna ropa azul y vn bordón en la mano e otras muchas figuras del mesmo largo e cayda del susodicho, que ay en todo el dicho paño otras setenta e dos anas al dicho respecto de vn ducado cada ana, montó todo veynte e syete mill maravedís" 28 .

Estos nueve tapices se encontraban en el alcázar de Segovia y se anotaron en una entrada anterior a la que incorpora los once que se enviaron a la Capilla Real en julio de 1505. Tal vez se pensó en darles el mismo destino, por lo que se creyó que también se habían entregado a Martín Velázquez ${ }^{29}$. No fue así; Fernando el Católico haciendo buena la cláusula del testamento de su esposa, decidió tomar para su cámara un importante número de paños entre los que se encontraban estos nueve: "estos seys paños de Ércoles y estos tres paños del Pelegrino se vendieron al rey nuestro señor por preçio de CCCXLII U maravedís"30. Cantidad muy elevada, aunque debió ser inferior al verdadero valor, pues el rey de Aragón se hizo con varios tapices del tesoro de Isabel la Católica después de imponer una segunda tasación, que evidentemente rebajaba el precio inicial. Así, sirva el ejemplo, adquirió un magnífico paño de la Resurrección de Lázaro, hoy en La Seo de Zaragoza, por 84.075 maravedís, cuando la apreciación original fue de $150.000^{31}$.

Fernando el Católico no se limitó a disponer de los bienes de su esposa, sino que también quiso contribuir personalmente a incrementar el patrimonio de su fundación, de manera que determinó en su testamento que se enviasen cuatro paños de sus pertenencias a la Capilla Real: “... sean tomados los hornamentos todos de seda e de brocado e broslados de nuestra capilla [...] y los paños de los syete gozos de Nuestra Señora y el paño de la ystoria de los tres estados y será

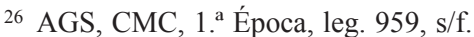

27 Mateo Gómez y Mateo Viñes, 1997: 297-302. Bando De La Campa, 2007: 85-108.

28 AGS, CMC, 1. 'ápoca, leg. 959, s/f.

${ }^{29}$ Los tapices fueron publicados por Ferrandis, 1943: 140-141, y por SÁnChez CANTón, 1950: 109-110. El primero no dice nada respecto a su destino mientras que Sánchez Cantón afirma que ocho se entregaron a Martín Velázquez (el último de los seis de la Historia de Hércules, sin declarar la razón, no lo incluye a pesar de que hay continuidad en la relación).

${ }^{30} \mathrm{AGS}, \mathrm{CMC}, 1{ }^{\mathrm{a}}$ Época, leg. 81, fol. CXXXVII. Torre y DEL CERro, 1974: 205-206, anota que los compró el rey por 342.000 maravedís, pero no detalla el precio de cada uno.

31 AGS, CMC, 1. ${ }^{a}$ Época, leg. 85, fol. 5/105. Herrero Carretero, 2004: 32-33. Zalama, 2010: 58. Zalama, 2011: 25 .

Arch. esp. arte, LXXXVII, 345, ENERO-MARZO 2014, 1-14

ISSN: 0004-0428, eISSN: 1988-8511, doi: 10.3989/aearte.2014.01 


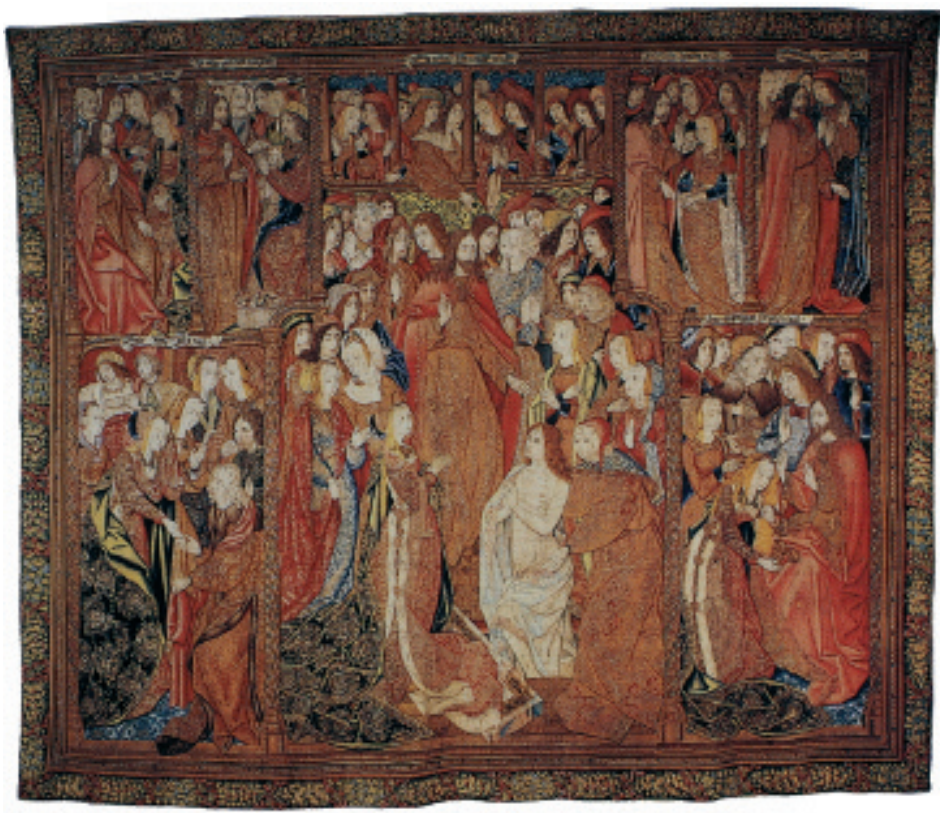

Fig. 2. Resurrección de Lázaro, c. 1500. Tapiz manufacturado en Bruselas. Lana, seda y oro. $393 \times 466 \mathrm{~cm}$. Zaragoza, Museo de Tapices de La Seo.

todo lo susodicho sacado lo que al monesterio de Poblete en el siguiente capítulo desto dexamos dado..." 32 . Los paños de los Siete Gozos de Nuestra Señora pertenecieron al rey de Aragón Fernando I al menos desde 1436. Posteriormente en poder del príncipe Carlos de Viana, pasaron a su padre Juan II, y se relacionan en el registro de sus bienes realizado a la muerte del rey en $1479^{33}$. Se trataba de tres tapices que aparecen identificados en un inventario de los objetos pertenecientes a la Capilla Real realizado en 1536: “...paño de los gozos de Nuestra Señora que tiene la Anunciación y Nacimiento y Reyes" (en una misma pieza se sumaban los Gozos primero, tercero y cuarto, según la estructura actual de la devoción franciscana); "otro tiene la Resurrección y Ascensión y Espíritu Santo" (se trata del Gozo sexto) y un "paño más chico que los otros, tiene el gozo de la Asunción de Nuestra Señora (el séptimo) ${ }^{34}$.

El otro tapiz que el rey de Aragón ordenaba enviar a la que iba a ser su última morada era el de los Tres estados. Como los anteriores, se encontraba en el monasterio de Poblet y también procedía del tesoro de su padre. En el inventario post mortem de Juan II aparece como "la ystoria de las edats" ${ }^{35}$, y en el de la Capilla Real de 1536 se cita como "de los tres estados, el estado eclesiástico y el estado real y el estado de los labradores" "36. Nada se dice de su tasación, solo que este último y el primero de los Siete Gozos de Nuestra Señora "eran grandes", mientras que el tercero se define como "más chico", aunque no es arriesgado suponer que se trataba de piezas de gran calidad que en ningún caso desmerecerían de los paños procedentes del tesoro de Isabel la Católica.

32 AGS, PR, leg. 29, doc. 52.

33 Zalama y Pascual Molina, 2012: 294.

34 El inventario fue publicado por GALLEGo BuRín, 1953: 45-48.

35 Zalama y Pascual Molina, 2012: 295.

36 Gallego y Burín, 1953: 45. 


\section{Fortuna de los tapices}

Contemplados los cuatro paños de Fernando el Católico, en total fueron veintiséis los tapices que dispusieron para la Capilla Real, la mayoría de los bienes de la reina Isabel (22 paños) aunque todos por decisión de su esposo. No debieron ser más, pues así lo confirma el inventario de 1536, por lo que los objetos entregados al limosnero Pedro García de Atienza el 13 de marzo de 1505 , entre los que se lista un considerable número bajo el epígrafe "Paños de lienço de devoçión", no debían ser tapices propiamente dichos sino pinturas y bordados; además no hay seguridad de que su destino fuese la Capilla Real, pues se dice que "se dieron e entregaron a Pero Garçía limosnero para lleuar a Granada", lo que admite que fuesen para las diferentes iglesias y monasterios del recién conquistado reino y especialmente de la capital ${ }^{37}$.

Sin embargo, aunque la orden de entrega sumaba veintiséis paños ${ }^{38}$, uno no debió llegar a su destino. Según el primer registro conocido de los objetos que conservaba la Capilla Real, en 1536 solo había veinticinco tapices. Todas las entradas se pueden identificar con seguridad con los paños de los Reyes Católicos ${ }^{39}$, pero falta uno, el "paño grande de deboçión de lana y seda y oro que tyene en medio el cruçifixo con los ladrones y a la mano derecha la salutaçión de Nuestra Señora, tiene de largo quinze varas e de cayda quatro varas y media", que en principio formaba parte del envío realizado en julio de 1505. Probablemente nunca ingresó en la Capilla Real, pues resulta difícil de aceptar su desaparición solo veinte años después, y es que quizá Fernando el Católico decidió en el último momento quedarse con el paño como hizo con los de las series de Hércules o del Peregrino. De hecho, entre los tapices que el arzobispo Alonso de Aragón dejó a La Seo se relaciona "un paño mediano rico con mucha seda y oro y con la hystoria de la Passión y los dos ladrones cerca de la cruz, es paño notabilíssimo", y sabemos que en buena medida los tapices del prelado procedían de su padre, el rey Fernando el Católico ${ }^{40}$. No obstante la identidad en el tema central, el que perteneció al arzobispo se inventarió como "un paño mediano"41, lo que no concuerda con el que perteneció a Isabel la Católica, del que se dice que era "grande", lo que era cierto pues alcanzaba "quinze varas" de largo, más de 12,5 metros, por lo que habría que pensar en un error en la apreciación del tamaño por parte de quien realizó el registro de los tapices de Alonso de Aragón, pues tanto por la temática como por el devenir del tapiz, no parece arriesgado concluir que se trataba del mismo.

Un siglo después de llegar a la Capilla Real, los tapices se habían deteriorado hasta el punto de que se solicitó a Felipe III que procediese a restaurarlos ${ }^{42}$. Encomiable deseo por parte de los capellanes, que incluso apuntaban el nombre de un tapicero flamenco para que llevase a cabo los trabajos. No sabemos si se realizó la restauración, pero en cualquier caso la suerte estaba echada para los paños. La pérdida de valor que los tapices sufrieron con el paso de los años, llevó a que en 1679 se quemase parte de uno para obtener la plata que incorporaba. El desinterés por las otrora piezas principales de los tesoros reales era tan grande como el abandono al que se habían sometido, de manera que en 1704 se decía que los tapices estaban "biejos y maltratados". Ni

${ }^{37} \mathrm{AGS}, \mathrm{CMC}, 1 .{ }^{\mathrm{a}}$ Época, leg. 959, s/f. La entrega se realizó a la misma persona el día antes que los once primeros paños, pero son dos partidas perfectamente diferenciadas.

38 Curiosamente el número coincide con el declarado por SÁNChEZ CANTÓn: 1950, 96 y 100, que creía que del tesoro de la reina se habían tomado 19 y que el rey había entregado otros 7.

39 GALlego Y Burín, 1953: 45-48, detalla las entradas del inventario de 1536, tratando de hacer coincidir los tapices con los publicados por Sánchez Cantón, lo que evidentemente no cuadra porque se desconocía cuáles habían sido. Por el contrario, si se cotejan los paños que sabemos que se enviaron a la Capilla Real con los listados en el inventario aludido, no hay dudas de su identidad.

40 Zalama y Pascual Molina, 2012: 300-302.

41 TORRA DE ARANA et al., 1985: 324-325.

42 Gallego y Burín, 1953; 48.

Arch. esp. arte, LXXXVII, 345, ENERO-MARZO 2014, 1-14

ISSN: 0004-0428, eISSN: 1988-8511, doi: 10.3989/aearte.2014.01 
siquiera se guardaba memoria cierta de su procedencia, pues se creía que los había donado Carlos $\mathrm{V}$, y un año más tarde se procedió a quemar los más deteriorados, obteniendo 20 libras y 4 onzas de plata, lo que da idea de la riqueza de los paños ahora convertidos en vil metal. Ya no se trataba de abandono; sencillamente se habían destruido. La merma llevó a que a mediados del siglo XVIII solo se conservasen dieciséis, de los que en realidad uno no se corresponde con los primitivos, pues el paño anotado como "de los apóstoles con un cardenal de rodillas en medio" no coincide con ninguno de los inventariados en 1536. A partir de 1777 la documentación de la Capilla Real no hace mención a los tapices y en época reciente no se tiene noticia del destino de los que sobrevivieron a las quemas documentadas, aunque, desgraciadamente, tal vez corrieron la misma suerte poco tiempo después ${ }^{43}$.

\section{Aprecio y desinterés posterior por los paños}

El triste final de los tapices consignados por los Reyes Católicos a su capilla en Granada desafortunadamente no es algo singular. Los paños acabaron en la hoguera porque estaban deteriorados, estado al que habían llegado por el desinterés cuando no el desprecio que se fue gestando a lo largo del siglo XVII y que alcanzó su mayor desapego en las dos centurias siguientes, e incluso en buena parte del siglo XX. Se trataba de piezas muy costosas, tanto por los materiales empleados en su hechura - finas lanas, seda y con frecuencia plata y aun oro- como por una laboriosa y larga manufactura que conllevaba meses de trabajo, cuando no años. Poseer ricos paños en los siglos XV y XVI era sinónimo de lujo y la ostentación formaba parte de cualquier puesta en escena de los poderosos. Tal era el afán por mostrarse con todas las riquezas posibles que los Reyes Católicos se vieron obligados a dictar sucesivas órdenes para impedir el uso abusivo de brocados, terciopelos y todo tipo de ricas telas (y joyas cuando se podía), por parte de sus súbditos ${ }^{44}$. A juzgar por las reiteradas órdenes, parece que no se cumplían y que se prefería transgredir la ley antes que renunciar a la ostentación ${ }^{45}$. Y es que ni siquiera Isabel la Católica era capaz de sustraerse al boato. Fray Hernando de Talavera le recriminaba en 1493, "el gasto de las ropas y nueuas vestiduras" que se había realizado con motivo de las fiestas en Perpiñán, a lo que la reina respondió que "trajes nueuos no hubo [...] que todo lo que allí vestí abía vestido desde que estamos en Aragón" "46. Justificaciones un tanto forzadas ¿se habría atrevido el arzobispo de Granada a pedir explicaciones a la soberana sin tener la certeza de que lo que decía era cierto?, que no se corresponden con otros testimonios como el del aragonés Pere Çavertes, presente en los festejos y que deslumbrado ante la riqueza escribió: "la sereníssima senoyra reyna isqué tant sumptuosament abillada que se extimaua lo que portaua valler cent milia ducats" ${ }^{47}$. La cantidad se antoja exagerada, pero conocemos que la reina tenía vestidos riquísimos como "un ábito de terciopelo carmesí que tiene en el dicho ábito una manga larga en dos tyras forradas en oro tyrado e la otra corta con su buelta abierta e un golpe en ella que tiene el dicho ábito tres tiras de oro tyrado por los costados e trasera de ancho de tres dedos forradas çebty amarillo, que tiene el dicho ábito cosidas en él ochoçientas e catorze pieças de chapería de oro", plagado de "rosicas de oro" y lazadas del mismo metal que cobijaban 1.167 perlas ${ }^{48}$. Por otra parte, sabemos

43 La fortuna de los paños en Gallego y BuRín, 1953: 48-52.

44 SEMPERE y GuARINOS, 1788: 3-22.

45 Al finalizar el siglo XV una vara de brocado se cotizaba en 10.000 maravedís. LADERo QUESADA, 2003: 97-99.

46 Clemencín, 1821: 351-383. El original de la carta de Talavera en AGS, Estado, leg. 1-II, fol. 343. La carta de la reina no se conserva; hay una copia en la Biblioteca del Real Monasterio de El Escorial, L-I-13, fols. 9-18.

47 BAYERri Bertoméu, 1963-1965: 358.

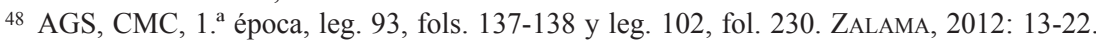


que además de los vestidos, exponer toda la vajilla y los ricos tapices era costumbre habitual en cualquier recepción por parte de los reyes y los nobles, y en lo que se refiere a los paños también se colgaban en las calles y plazas, no solo en el interior de palacios e iglesias ${ }^{49}$.

Arte, tal como lo entendemos en la actualidad, no era concebible al margen del lujo; es más, los objetos se valoraban primero por sus materiales y solo al final por lo "artístico". Esto se puede apreciar perfectamente en los inventarios de bienes de los poderosos, donde las obras de pincel solo aparecen en último lugar. A modo de ejemplo, llama la atención cómo las 47 tablas del llamado Políptico de Isabel la Católica, atribuidas a Juan de Flandes y Michel Sittow, alcanzaron una tasación de 76.500 maravedís $^{50}$, la mitad que el tapiz de la Resurrección de Lázaro que adquirió Fernando el Católico, o cuatro paños de la Historia de Nabucodonosor, por cada uno de los cuales el rey de Aragón pagó tanto como se habían tasado todas las tablas del políptico ${ }^{51}$. Por si fuera poco, la mayor parte de las tablas no encontraron comprador hasta año y medio después de comenzar la almoneda de los bienes de la reina, cuando por supuesto ya se habían vendido todos los tapices, y las adquirió Felipe el Hermoso ${ }^{52}$. No es un caso aislado, pues la venta de las pinturas de Isabel la Católica fue frustrante, a pesar de sus bajísimos precios, como los 170 maravedís en que se tasó una tabla atribuida al Bosco, por llevar escrito "Jeronimus", que representaba a la Magdalena ${ }^{53}$. Frente a esto, conocido es el interés por los paños por monarcas como Enrique VIII de Inglaterra ${ }^{54}$, Francisco I de Francia y especialmente Carlos V ${ }^{55}$. Por su parte, Felipe II no dudó en pagar 370.385 maravedís por los cuatro Paños de Oro, que pertenecieron a su abuela, la reina Juana I, y que Carlos V sacó de Tordesillas en $1526^{56}$. El rey Prudente sabía del valor de los paños y ordenó a sus herederos "que no vendan, ni enajenen, ni empeñen cosa alguna", y de manera singular "las piedras preciosas, joyas de valor y tapicería rica..."57.

Durante el siglo XVI la primacía de los tapices se mantuvo, no obstante, la pintura comenzó a erigirse en la principal de las artes. Con rapidez se fue imponiendo la nueva idea de lo artístico en la que la singularidad era lo más apreciado, de manera que las series de tapices, con frecuencia repetidas, acabaron cediendo su puesto preeminente a las arti del disegno. Con esta idea generalizada, no fueron pocos los paños que se perdieron. Algunos acabaron en manos de nuevos ricos ávidos de mostrar su poderío mediante la adquisición de todo lo que estuviese en venta. Así, el duque de Alba puso a la venta "75 tapisseries de premier ordre" en París en $1877^{58}$, y fueron muchas las iglesias y catedrales -Palencia, Burgos, Toledo...- que se despojaron de sus paños a cambio de, en ocasiones, considerables sumas. Mediante marchantes interpuestos, magnates norteamericanos, entre los que destaca William R. Hearst, se hicieron con los mejores tapices $^{59}$. No obstante, muchos se habían perdido ya y otros estaban tan deteriorados que, como ocurrió con los de la Capilla Real, se acabaron quemando para extraer con facilidad los metales preciosos, a veces en cantidades muy reducidas. El desinterés continuó hasta épocas recientes, pues según cuenta Federico Marés, a comienzos del pasado siglo se seguían quemando, aunque se podían salvar de la hoguera si se pagaban "10, 15 o 20 durillos" por tapiz ${ }^{60}$. Esto es lo que

\footnotetext{
49 Zalama, 2011: 25.

50 SÁNCHEZ CANTÓN, 1930: 97-133.

51 TORRE y DEL CERro, 1974: 206-297.

52 ZALAMA, 2006: 38.

53 SÁNCHeZ CANTÓN, 1950: 182. Zalama, 2008: 54.

54 CAMPBell, 2007.

55 CHECA, 2008.

56 Zalama, 2010: 306-310. Zalama, 2013: 53-69.

57 Herrero Carretero, 1994: 289-290.

58 DuQue de Alba y Berwick: 1877.

59 Merino de Cáceres y Martínez Ruiz, 2012.

60 Marés Deulovol, 1977: 181.
}

Arch. esp. arte, LXXXVII, 345, ENERO-MARZO 2014, 1-14

ISSN: 0004-0428, eISSN: 1988-8511, doi: 10.3989/aearte.2014.01 
hacían algunos anticuarios atendiendo a la posibilidad de negocio, pero gracias a ello se salvaron piezas que de lo contrario habrían corrido la misma suerte que los magníficos paños entregados por los Reyes Católicos a su capilla en Granada.

\section{APÉNDICE DOCUMENTAL}

\section{Cuentas del camarero Sancho de Paredes}

Vn paño de deboçión de lana e seda que tiene vn cruçifixo puesto en la columna [...] e por horla vnas viñetas verdes en canpo amarillo, que tiene de largo tres varas e tres quartas e de cayda quatro varas e quatras e medido por anas tiene veynte e quatro anas el qual es guarnesçido de lienço de angeo en que entreron tres varas.

Otro paño de deuoçión que se dize eçe homo de seda e lana de muchas colores [...] tiene por orla vnas viñetas verdes en vn canpo amarillo que tiene de largo tres varas e tres quartas e de cayda otro tanto e medido por anas tiene veynte e vna anas e tres quartas el qual está guarnesçido de lienço de angeo.

Otro paño de deboçión del prendimiento de Nuestro Señor de lana e seda que tiene en el medio Nuestro Señor e Judas junto con el que le viene a dar paz [...] tiene por horla vnas viñetas verdes en vn campo verde están con vnas flores coloradas, que tiene de largo dos varas e tres quartas e de cayda tres varas e media largas e medido por anas tiene quinze anas el qual es guarnesçido de lienço angeo.

Otro paño de deboçión pequeño de seda e lana, está Nuestro Señor quando pidió agua a la samaritana bestido de vna vestidura morada con vn letrero de la mano de Nuestro Señor a la boca de la jarra de la samaritana [...] tiene de largo dos varas e media e de cayda tres varas e quarta, medido por anas tiene doze anas.

Otro paño de deboçión de seda blanca que tiene a Nuestro Señor con vna bestidura de púrpura morada con las manos atadas atrás con la corona de espinas en la cabeça e donde está con Pilatus que se lava las manos [...] tiene de largo dos varas e media e de cayda tres varas e dos terçias escasas, medio por anas tiene quatorze anas.

Otro paño de deboçión e en lo baxo del está Nuestro Señor con vna bestidura de púrpura morada donde laba los pies a sus disçípulos [...] de largo tres varas e terçia escasas e de cayda tres varas e diez dozabos, medido por anas tiene veynte anas y media.

Otro paño de deboçión en que está Nuestra Señora con el Niño en los braços con vna saya colorada e vn manto azul e Josep delante con el asno del cabestro [...] es el dicho paño de la huyda a Egipto, que tyene de largo quatro varas e dos terçias e de cayda tres varas e dos terçias que medido por anas tiene veynte e syete anas.

Otro paño de chiquito de deboçión que tiene en el medio a santa Bárbara [...] tiene de largo dos varas e media escasas e de cayda tres varas e quarta e medido por anas tiene dose anas e tres quartas.

Otro paño de deboçión del nasçimiento [...] tiene de largo tres varas e media que tiene diez e seys anas.

Otro paño de deboçión pequeño que tiene tres figuras que es de la ystoria de Apocalipsi [...] tiene de largo dos varas e media e de cayda tres varas que tiene doze anas.

Otro paño de deboçión que tiene estas ystorias a la parte de ençima de la mano derecha la salutaçión e junto con ella la çircunçiçión e luego quatro ángeles que están cantando e luego Nuestra Señora con el Niño en los braços e Josep [...] tiene de largo cinco varas e quarta e de cayda quatro varas que tiene treinta e çinco anas.

[...] las quales dichas cosas [...] se dieron y entregaron a Pedro Garçía de Atiença limosnero de la reyna nuestra señora que santa gloria aya en la çibdad de Toro a catorse días del mes de março de mill e quinientos e çinco años para las lleuar a la capilla Real de la çibdad de Granada

Arch. esp. arte, LXXXVII, 345, ENERO-MARZO 2014, 1-14 ISSN: 0004-0428, eISSN: 1988-8511, doi: 10.3989/aearte.2014.01 
por nómina del rey nuestro señor e de los testamentarios de su altesa, fecho en la dicha çibdad de Toro este mes e año susodichos.

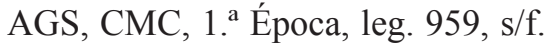

\section{Cuentas del camarero Sancho de Paredes}

Que se vos haze cargo más que reçebistes vn paño de devoçión que en lo baxo del está Nuestro Señor con vna vestidura de púrpura dorada [...] el qual se compró de Matis de Guirla tapiçero a preçio de mill maravedís cada ana el qual se guarnesçió en lienço angeo de vuestro cargo en que entró vara e quarta los quales dichos seys paños vos ovistes reçebido del dicho Matis de Guirla en la villa de Medina del Campo a quinze días del mes de enero de mill e quinientos e quatro años.

Vn paño de deboçión en que está Nuestra señora con el Niño [...] se compró de Matis de Guirla al preçio de quatroçientas e çinquenta maravedís el ana el qual se guarnesçió en lienço angeo de vuestro cargo en que estraron tres varas que asimismo vos reçebistes ente dicho paño en la dicha villa de Medina del Campo a quinze días del mes de enero de mill e quinientos e quatro años del susodicho Matis de Guirla tapiçero.

Vn paño chequito de devoçión que tiene en el medio a santa Bárbara [...] medido por anas tiene doze anas e tres quartas el qual se conpró de Matis de Guirla a preçio de noveçientos e treynta e siete maravedís e medio el ana el qual se guarnesçió en lienço angeo de vuestro cargo en que entreron vara e media el qual reçebistes en la villa de Medina del Campo a quinze días del mes de enero de mill e quinientos e quatro años.

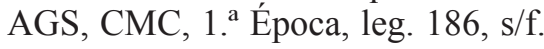

\section{BIBLIOGRAFÍA}

Alonso Ruiz, Begoña, "Las obras reales en Granada (1506-1513)", Cuadernos de Arte. Universidad de Granada, 37 (2006), pp. 339-369.

Alonso Ruiz, Begoña, "Un nuevo proyecto para la Capilla Real de Granada", Goya, 318 (2007), pp. 131140.

Azcárate, José María, Datos histórico-artísticos de fines del siglo XV y principios del XVI, Zaragoza, 1982.

Bando de la Campa, Flor María, "Le pèlerinage de vie humaine versus El pelegrino de la vida humana", Cahiers de linguistique hispanique médiévale, 30 (2007), pp. 85-108.

Bayerri Bertoméu, Enrique, "Las relaciones del rey don Fernando con el marquesado de Tortosa", Jerónimo Zurita. Cuadernos de Historia, 16-18 (1963-1965), pp. 347-384.

Campbell, Thomas P., Henry VIII and the Art of Majesty. Tapestries at the Tudor Court, New Haven y Londres, 2007.

Checa, Fernando, Tapisseries flamandes. Pour les ducs de Bourgogne, l'empereur Charles Quint et le roi Philippe II, Bruselas (ed. en español, Tesoros de la Corona de España. Tapices flamencos en el Siglo de Oro, Bruselas, 2010).

Clemencín, Diego, Elogio de la reina Católica doña Isabel, Madrid, 1821.

Delmarcel, Guy, "La collection de tapisseries de la reine Isabelle de Castille (1451-1504). Quelques refléxions critiques", en Checa, Fernando y García García, Bernardo J. (eds.), El arte en la corte de los Reyes Católicos. Rutas artísticas a principios de la Edad Moderna, Madrid, 2005, pp. 287-303.

Duque de Alba y Berwick, Collection de S. A. le Duc de Berwick et d'Alba, Exposition et ventes à l'Hôtel Drouot du 7 avril au 20 avril, 1877.

Ferrandis, José, Datos documentales para la Historia del Arte español, III. Inventarios reales (Juan II a Juana la Loca), Madrid, 1943.

Gallego y Burín, Antonio, La Capilla Real de Granada, Madrid, 1931.

Arch. esp. arte, LXXXVII, 345, ENERO-MARZO 2014, 1-14

ISSN: 0004-0428, eISSN: 1988-8511, doi: 10.3989/aearte.2014.01 
Gallego y Burín, Antonio, Nuevos datos sobre la Capilla Real de Granada, Madrid, 1953.

Gómez-Moreno, Manuel, "Sobre el Renacimiento en Castilla. II. En la Capilla Real de Granada", Archivo Español de Arte y Arqueología, I (1925), pp. 245-288.

Herrero Carretero, Concha, "Las tapicerías ricas del alcázar de Madrid”, en Checa, Fernando (dir.), El Real Alcázar de Madrid. Dos siglos de arquitectura y coleccionismo en la corte de los reyes de España, Madrid, 1994, pp. 288-307.

Herrero Carretero, Concha, Tapices de Isabel la Católica. Origen de la colección real española, Madrid, 2004.

Ladero Quesada, Miguel Ángel, La armada de Flandes. Un episodio de la política naval de los Reyes Católicos (1496-1497), Madrid, 2003.

Marés Deulovol, Federico, El mundo fascinante del coleccionismo y las antigüedades, Barcelona, 1977.

Mateo Gómez, Isabel y Mateo Viñes, Julián, "El peregrino de la vida humana del Bosco", Archivo Español de Arte, LXX (1997), pp. 297-302.

Merino de Cáceres, José Miguel y Martínez Ruiz, María José, La destrucción del patrimonio artístico español. W. R. Hearst: el gran acaparador, Madrid, 2012.

Redondo Cantera, María José, "La Capilla Real de Granada como panteón dinástico durante los reinado de Carlos V y Felipe II: problemas e indecisiones. Nuevos datos sobre el sepulcro de Felipe el Hermoso y Juana la Loca", en Borngässer, Barbara et al. (eds.), Grabkunst und Spulkralkultur in Spanien und Portugal, Madrid, 2006, pp. 403-418.

Rossenthal, Earl E., "El primer contrato de la Capilla Real", Cuadernos de Arte. Universidad de Granada, XI-21 (1971-1974), pp. 13-36.

Sánchez Cantón, Francisco Javier, "El retablo de la reina Católica”, Archivo Español de Arte y Arqueología, VI (1930), pp. 97-133.

Sánchez Cantón, Francisco Javier, Libros, tapices y cuadros que coleccionó Isabel la Católica, Madrid, 1950.

Sempere y Guarinos, José, Historia del luxo, y de las leyes suntuarias, II, Madrid, 1788.

Torra de Arana, Eduardo, et al., Los tapices de La Seo de Zaragoza, Zaragoza, 1985.

Torre y del Cerro, Antonio de la, Testamentaría de Isabel la Católica, Barcelona, 1974 (2.a ed.).

Zalama, Miguel Á., "Felipe el Hermoso y las artes", en Zalama, Miguel Á. y Vandenbroeck, Paul (dirs.), Felipe I el Hermoso. La belleza y la locura, Madrid, 2006, pp. 17-48.

Zalama, Miguel Á., "La infructuosa venta en almoneda de las pinturas de Isabel la Católica", Boletín del Seminario de Arte y Arqueología (Arte), LXXIV (2008), pp. 43-64.

Zalama, Miguel Á., Juana I. Arte, poder y cultura en torno a una reina que no gobernó, Madrid, 2010.

Zalama, Miguel Á., "Primacía de los tapices entre las artes figurativas en España en los siglos XV y XVI", en Checa, Fernando y García, Bernardo J. (eds.), Los Triunfos de Aracne. Tapices flamencos de los Austrias en el Renacimiento, Madrid, 2011, pp. 17-36.

Zalama, Miguel Á., "Oro, perlas, brocados... La ostentación en el vestir en la corte de los Reyes Católicos", Revista de Estudios Colombinos, 8 (2012), pp. 13-22.

Zalama, Miguel Á., "Origen y destino de la colección de tapices de la reina Juana I", Checa, Fernando (dir.), Museo Imperial. El coleccionismo artístico de los Austrias en el siglo XVI, Madrid, 2013, pp. 53-69.

Zalama, Miguel Á. y Pascual Molina, Jesús F., “Tapices de Juan II de Aragón y Fernando el Católico en La Seo de Zaragoza”, Boletín Museo e Instituto Camón Aznar, 109 (2012), pp. 285-320.

Fecha de recepción: 20-XII-2012

Fecha de aceptación: 17-VI-2013

Arch. esp. arte, LXXXVII, 345, ENERO-MARZO 2014, 1-14 ISSN: 0004-0428, eISSN: 1988-8511, doi: 10.3989/aearte.2014.01 